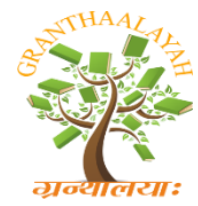

INTERNATIONAL JOURNAL OF RESEARCH GRANTHAALAYAH A knowledge Repository

Management

\title{
RISK PERCEPTION IN E-COMMERCE: A HOLISTIC REVIEW OF EMERGING ONLINE SHOPPING IN INDIA
}

\author{
Muhammad Shafeeque A.P. ${ }^{* 1}$, Thomachan K.T. ${ }^{2}$ \\ ${ }^{1} \mathrm{PhD}$ Research Scholar (Economics), Madras Institute of Development Studies (MIDS), \\ Chennai-600020, India \\ ${ }^{2}$ Associate Professor, Department of Economics, St. Joseph's College (Autonomous), Devagiri, \\ Kozhikode, Kerala, India
}

DOI: https://doi.org/10.29121/granthaalayah.v5.i6.2017.2021

\begin{abstract}
This paper examines the perceived risks associated with online shopping. Perceived risk defined as a consumer's belief about the potential losses or other negative outcomes from transacting on the internet. Fifty-eight percent of internet users describe online shopping as a frustrating, confusing, and overwhelming activity. Even though majority of the online shoppers have perceive risk, religion, income and occupation are not found to be significant factors in risk perception.
\end{abstract}

Keywords: E-Commerce; Online Shopping; Risk Perception; B2C; Kruskal Value; Chi-Square.

Cite This Article: Muhammad Shafeeque A.P., and Thomachan K.T.. (2017). "RISK PERCEPTION IN E-COMMERCE: A HOLISTIC REVIEW OF EMERGING ONLINE SHOPPING IN INDIA.” International Journal of Research - Granthaalayah, 5(6), 231-239. https://doi.org/10.29121/granthaalayah.v5.i6.2017.2021.

\section{Introduction}

Modern world is rightly described as 'Internet world' because daily life is all about finger tips in this electronic era. Electronic commerce is a powerful concept and process as it has fundamentally changed the current human life. Electronic commerce is one of the main areas of Information, Technology and Communication (ICT). This style of trading has received a major boost in recent years due to the enormous benefits associated with it. It is claimed that electronic commerce has surpassed many of the limitations of traditional business. Online shopping is a form of electronic commerce which allows consumers to directly buy goods or services from a seller over the internet using a web browser. It is also known as E-tail, from electronic retail or E-shopping. 
The volume of online shopping has been rapidly growing all over the world. The percent of online users who have made an internet purchase was $85 \%$ in 2010 in the US, and the number of US digital shoppers is expected to grow from 137 million in 2010 to 175 million in 2017. Clearly, the statistics imply the crucial role of e-commerce in world trade and there have been significant benefits both for sellers and buyers. Online shopping improves market efficiency and enhances welfare because of the ability of shoppers to make better quality decisions while buying online. This is because there appears to be a strong link between product varieties of online shopping and social welfare.

Online buying is growing exponentially throughout the world. UK is biggest online shopping nation in the world followed by Denmark, Norway and Korea. In Nigeria and other African countries the number of users is still far below the world average which is around $30 \%$. Now-adays due to the availability of faster internet networks e-commerce activities are expanding at a faster rate in Nigeria, South Africa and Kenya. In South Africa, 51\% of individuals with internet access shop online whereas, in Kenya, only 18-24\% makes online purchases. In Nigeria approximately $28 \%$ of the population has internet access according to ITU figure. According to a study the swiftness of online shopping in Pakistan is sluggish compared to India and other countries. The total value of e-commerce activities in India has surpassed Rs.5.7 billion during 2004-05 and Rs.23 billion by the year 2006-07. According to Rajan Anandan, VP \& Managing Director of Google India, with approximately 8 million Indians shopping online in 2012, online shopping industry in India is growing rapidly and will continue to see exponential growth. According to a survey conducted by IMRB International and IAMAI, there was an estimate of 137 million internet users in the country as of June 2012 of which 99 million were from urban parts of the country, the remaining 38 million were from rural India. So, online shopping is flourishing not only in metros and urban areas but also in rural areas.

Although there is an increase in the overall volume of e-commerce, there is still a need to enhance the total value created by online shopping in order to provide further benefits in terms of raising welfare. But this is a challenging process because the most significant obstacle to reaching this goal is the high level of consumers' perception of the risk associated with the shopping on the internet. Perceived risk is an important barrier for online consumers because it threatens the operation of the e-commerce, making security issues a fundamental concern. Risk is a much more salient concern in e-commerce than in many other social and economic interactions involving uncertainty due to the nature of the financial transactions and multiple levels of uncertainties. However, a vast body of the literature investigates increase in the volume of e-commerce by reducing risk issues. Hence, both scholars and online retailers are increasingly concerned about reducing risk perceptions in online shopping.

\section{Statement of the Problem}

Emergence of online shopping has considerable impact on modern life style. The development of e-commerce has increased the popularity of online shopping worldwide especially with the advent of Technology Acceptance Model (TAM). It was developed by Davis (1989), adopted from the Theory of Reasoned Action, which is designed to explain human behaviours in general. In accordance with this theory, the TAM proposes that the use of computers is determined by behavioural intention, which measures individual's intention to perform a specific behaviour. The 
TAM proposes two specific beliefs; perceived ease of use and perceived usefulness, which determine individual's intention to use a technology.

Business to Consumer (B2C) is an internet and electronic commerce (e-commerce) model that denotes a financial transaction or online sale between a business and consumer. B2C is also known as business-to-consumers. India is one of the major countries having a wide range of internet related activities. It was estimated that increasing internet penetration and growing preference for shopping online will drive the e-commerce market in India to USD 15 billion by 2016 with a whopping 100 million people going online to shop, today.

Despite of all these merits, online shopping has risks too. Perceived risk defined as a consumer's belief about the potential losses or other negative outcomes from transacting on the internet. Fifty-eight percent of internet users describe online shopping as a frustrating, confusing, and overwhelming activity. Past research has found that a major inhibitor of online shopping is the uncertainty or perceived risk associated with online purchasing. These risks are great barriers to the online purchase intention of customers. It includes social, financial, physical, performance, time, and psychological risks.

Most of the studies on e-commerce have concentrated mainly on risk aspect in various developed countries such as Saudi Arabia, Malaysia, and USA. All these studies show that customers dealing with online shopping face several risks. But the interesting question is why people still prefer online shopping to traditional shopping even if there are perceived risks. However, there is a need for systematic investigation of risk perception in online shopping since the literature on people's preference over traditional shopping in the presence of perceived risk has not received sufficient attention. So this particular study is an attempt to identify the various types of risk involved in e-commerce and why people still depends on online purchasing in the presence of perceived risk in a developing country like India.

\section{Literature Review}

There are very limited studies, which are directly relevant to the present study. They have been taken from journals, articles, $\mathrm{PhD}$ thesis and unpublished research work, concentrated mainly in developed countries like Saudi Arabia, USA, Malaysia, New Zealand etc. Still many recent researches have been found in developing countries like India and Jordan as well.

Dr. PanicosGeorgiades (2000), observed in his study that there were no differences between males and females in all three occupational groupings with regard to security and convenience of e-commerce. In particular respondents' attitudes toward security were found to be in agreement in that "they did not feel confident with the provision of information concerning their personal and financial details and that technology backing the internet is reliable". This suggests that companies can standardize their communications strategies aiming at alleviating the fears of internet users with regards to security concerns.

Sami Alsmadi (2002), study pointed out that most Jordanian consumers are likely to have enough knowledge and skills in using the computer and dealing with the internet, and have reasonable access to internet services, with a positive impression about the current presentation 
and promotion of companies' web sites on the internet. The study concluded that the issue of security of online transactions seems to be a major factor that restricts the willingness to make a better use of online shopping and also no significant differences in consumer attitudes due to demographic variables, with the exception of income.

Internet and Online Association of India (2005), made a survey of e-commerce security in 2005. The study was conducted through online and gathered information regarding the solicited information on the user's profile, internet usage, their perception of the security associated with transacting online, their areas of concern and factors that would increase their faith of online transactions. It was found that 45 percent of window shoppers at e-commerce sites represent an audience that shopping sites make informed decisions, a huge opportunity not exploited by marketers.

Syed Shah Alam and ZaharahBakar (2008), have investigated in their study the relationships between young consumers' perceptions of the factors that influence their intention to buy through online. The analytical results are generally consistent with consumers' perceptions of the customer service, reliability and trust of online purchasing. Trust has received the most consistent support as factors that influence online buying.

Amar Cheema and Purushottam Papatla (2009), made an attempt to study the relative importance of online information versus offline information for internet purchase. The study found that the relative importance of online information is higher for utilitarian products and the relative importance of online information decreases with increasing consumer internet experience and consumers' trust.

\section{Objectives}

The major objectives of this study are:

1) To identify the nature and magnitude of risk perception in online shopping.

2) To understand people's preference on online shopping over traditional shopping in the presence of perceived risk.

3) To examine the scope and future of online shopping in a world of casino economy.

\section{Data and Methodology}

To identify the types of risk perceived by online shoppers when considering an online purchase, data has been collected from both primary and secondary sources. Primary data for the study has been collected from 100 samples by using random sampling method. The study is purely based on sample surveys conducted among online shopping consumers in Kozhikode locality and sample consumers are those who buy commodities through online for more than one year. The sample survey was conducted by using a questionnaire.

The secondary data has been collected from online shopping surveys and reviews collected from various articles published in several journals, and E-journals and websites of Times of India, outlook, Deccan herald, CIOL and from various other references. For analysing the data and arrive at the logical conclusions, mathematical tools like percentage, ratios etc. and statistical 
tools like mean, standard deviation etc. have been used. To understand whether there is any difference in the perception about various types of risks, test of proportion (Z), Kruskal -Wallis (non-parametric test) $\mathrm{H}$ test and $\chi^{2}$ test of association has been used.

\section{The Kruskal -Wallis Test}

To assess whether there is any significant difference in risk perception of the consumers dealing with online shopping, the non-parametric alternative to one way ANOVA namely Kruskal Wallis Test has been employed.

The Kruskal -Wallis hypothesis for differences in population is:

$\mathrm{H}_{\mathrm{o}}$ : All k populations have the same distribution.

$\mathrm{H}_{1}$ : Not all $\mathrm{k}$ populations have the same distribution.

The Kruskal -Wallis test statistic is:

$$
H=\frac{12}{n(n+1)} \sum_{j=1}^{k} \frac{R_{j}^{2}}{n_{j}}-3(n+1)
$$

Where ' $n$ ' is the total sample size from k populations $n 1, n 2 \ldots n k$ and $R_{j}$ sum of the ranks from sample $\mathrm{j}(\mathrm{j}=1,2 \ldots \mathrm{k})$. We reject $\mathrm{H}_{\mathrm{o}}$ if sample $\mathrm{H}$ exceeds critical $\mathrm{H}$, at chosen level of significance.

\section{Chi-square Test $\left(\chi^{2}\right)$}

To assess the association between socio-economic characteristics (income, sex, religion and occupation) of sample consumers and risk perception in online shopping, we use the Chi-square test for independence.

The hypothesis for independence is:

$\mathrm{H}_{\mathrm{o}}$ : The two classification variables are independent of each other.

$\mathrm{H}_{1}$ : The two classification variables are not independent.

The Chi-square test statistic for independence is:

$$
\chi^{2}=\sum \frac{(O-E)}{E}^{2}
$$

\section{Test of Proportion}

To assess whether majority of the respondents have high risk perception, Z-test for proportions has been employed.

The hypothesis for proportions is:

Ho: $\mathrm{P} 0=0.5$

$\mathrm{H}_{1}: \mathrm{P} 0>0.5$

The test statistics is:

$$
z=\frac{\hat{p}-P 0}{\sqrt{P 0(1-P 0)} / n}
$$




\section{Results and Discussion}

This section outlines the major findings of sample survey. It examines the various socioeconomic characteristics of the sample consumers and also assesses the various types of risk perceptions involved in e-commerce and why people still depends on online purchasing in the presence of perceived risk. The study is based purely on sample survey conducted among online shopping consumers and the sample consumers are those who buy commodities through online for more than one year. The sample survey was conducted by using a questionnaire.

The study shows that majority of the sample consumers visit the online shopping websites weekly (36\%), followed by a monthly visit (32\%), and an annual visit (20\%). The rarely visit constitutes only (12\%). The study also reveals that most of the sample consumers purchased commodities using computer (66\%). Around $33 \%$ of sample consumers used mobile phone as medium of purchase. Most of the sample population used Amazon.in websites $(28 \%)$ followed by Flipkart.com (24\%) and Snapdeal.com (12\%). The online websites like E-bay.in, Naptol.com, Olx.in, and Shop clues etc. constitutes only (2\%), (2\%), (4\%) and $4 \%$ respectively.

The Kruskal -Wallis test of consumers' preferences on various online websites and its corresponding ranks are given below:

Table 1: Preference of Online Websites and Kruskal -Wallis $(\mathrm{H})$ test

\begin{tabular}{|c|c|c|}
\hline Median & Websites & \multirow{12}{*}{$\begin{array}{l}193.291 \mathrm{H} \\
\text { (corrected for ties) } \\
(0.000 * *\end{array}$} \\
\hline 2.00 & Flipkart & \\
\hline 6.00 & Snapdeal & \\
\hline 5.00 & Myntra & \\
\hline 2.00 & Amazon & \\
\hline 6.50 & Paytm & \\
\hline 6.00 & Jabong & \\
\hline 6.00 & Olx.in & \\
\hline 7.00 & Naptol & \\
\hline 6.00 & e-bay & \\
\hline 8.00 & shopclues & \\
\hline 5.00 & Total & \\
\hline
\end{tabular}

Source: Sample Survey

(Figure in brackets is p-value, ** indicates significance at $5 \%$ level.)

As the table suggests that there is difference in consumers rank and their preference over various online websites. Majority of the consumers prefer Flipkart and Amazon online websites. $(\mathrm{p}=0.000)$

It has been observed that the easy of accessibility is the major reason behind the consumers' preference over various online shopping websites (20\%). It is followed by the availability of more variety commodities (16\%), trustworthiness (14\%), and timely delivery of the commodities $(10 \%)$. The other reasons such as offers $(06 \%)$, discount $(06 \%)$, replacement guarantee $(06 \%)$, customer friendly $(06 \%)$, time saving $(06 \%)$, attractive $(04 \%)$, and high quality $(04 \%)$ are least important in the consumer's preference on various online shopping websites. 
Books are the most purchased commodities in online shopping $(36 \%)$ followed by footwear (18\%), gadgets $(16 \%)$ and clothing (16\%) items respectively. The other commodities like fashion accessories (10\%), automobiles (02\%), etc. are purchased less quantity. Most of the people choose cash on delivery method for purchases.

\section{Consumers Risk Perception in Online Shopping}

We examine below the extent of risk perception by online shoppers and the various socioeconomic factors determining it. Table 2 clearly suggests that majority of the consumers perceive the existence of risk associated with online shopping.

Table 2: Consumers Risk Perception in Online Shopping

\begin{tabular}{||l|l|l|l||}
\hline \hline Risk Involvement & Consumers & Percentage & \multirow{2}{*}{$\begin{array}{l}\mathbf{Z}=\mathbf{6 . 5 1} \\
(\mathbf{0 . 0 0 0}) * *\end{array}$} \\
\cline { 1 - 3 } Yes & 96 & 96 & \\
\hline No & 04 & 04 & \\
\hline Total & 100 & 100 & \\
\hline
\end{tabular}

Source: Sample Survey

(Figure in brackets is p-value, ** indicates significance at $5 \%$ level.)

Test of Proportion suggests that majority of the consumers perceive high risk associated with online shopping $(\mathrm{Z}=6.51, \mathrm{P}=0.000)$.

We also examine if there is any association between socio-economic characteristics of consumers such as income, sex, occupation and religion and their risk perception. To assess the association between income and risk perception, $\chi 2$ test of independence has been performed. Test results are given in Table 3.

Table 3: Income and Risk Perception

\begin{tabular}{|c|c|c|c|c|c|c|c|}
\hline \multirow[t]{2}{*}{ Income (R.s) } & \multicolumn{6}{|c|}{ Risk Perceptions } & \multirow{6}{*}{$\underset{(0.0978)^{*}}{\chi 2}=22.40$} \\
\hline & SR & D & TR & FR & $\mathbf{P R}$ & QR & \\
\hline Below 10000 & 04 & 08 & 03 & 18 & 09 & 08 & \\
\hline $10000-20000$ & 08 & 08 & 05 & 07 & 13 & 09 & \\
\hline $20000-50000$ & 12 & 07 & 04 & 08 & 06 & 13 & \\
\hline Above 50000 & 16 & 04 & 02 & 10 & 10 & 08 & \\
\hline
\end{tabular}

Source: Sample Survey

(Figure in brackets is p-value, ** indicates significance at $5 \%$ level.)

Where, SR- Security Risk, TR- Time Risk, FR- Financial Risk, PR- Product Risk, QRQuality Risk D- Damage.

As the table suggests there is no association between risk perception and income $\left(\chi^{2}=22.40\right.$, $\mathrm{P}=0.0978$ ).

To assess the association between sex and risk perception, $\chi 2$ test of independence has been performed. Test results are given in Table 4. 
Table 4: Sex and Risk Perception

\begin{tabular}{|c|c|c|c|c|c|c|c|}
\hline \multirow[t]{2}{*}{ Sex } & \multicolumn{6}{|c|}{ Risk Perceptions } & \multirow{4}{*}{$\begin{array}{l}\chi 2=5.47 \\
(0.3614)^{*}\end{array}$} \\
\hline & SR & D & TR & FR & PR & QR & \\
\hline Male & 08 & 06 & 04 & 15 & 09 & 08 & \\
\hline Female & 07 & 09 & 11 & 10 & 07 & 06 & \\
\hline
\end{tabular}

Source: Sample Survey

(Figure in brackets is p-value, * indicates significance at $5 \%$ level.)

As the table suggests there is no association between risk perception and sex.

$\left(\chi^{2}=5.47, \mathrm{p}=0.3614\right)$.

To assess the association between occupation and risk perception, $\chi 2$ test of independence has been performed. Test results are given in Table 5 .

Table 5: Occupation and Risk Perception

\begin{tabular}{|c|c|c|c|c|c|c|c|}
\hline \multirow[t]{2}{*}{ Occupation } & \multicolumn{6}{|c|}{ Risk Perceptions } & \multirow{4}{*}{$\begin{array}{l}\chi 2=2.43 \\
(0.7873) *\end{array}$} \\
\hline & SR & D & TR & FR & PR & QR & \\
\hline Govt. & 09 & 06 & 04 & 14 & 09 & 08 & \\
\hline Private & 14 & 05 & 07 & 12 & 07 & 07 & \\
\hline
\end{tabular}

Source: Sample Survey

(Figure in brackets is p-value, * indicates significance at 5\% level.)

As the table suggests there is no association between risk perception and occupation.

$\left(\chi^{2}=2.43, p=0.7873, p>0.05\right)$.

To assess the association between religion and risk perception, $\chi 2$ test of independence has been performed. Test results are given in Table 6.

Table 6: Religion and Risk Perception

\begin{tabular}{|c|c|c|c|c|c|c|c|}
\hline \multirow[t]{2}{*}{ Religion } & \multicolumn{6}{|c|}{ Risk Perceptions } & \multirow{5}{*}{$\begin{array}{l}\chi 2=2.34 \\
(0.9931)^{*}\end{array}$} \\
\hline & SR & D & TR & FR & PR & QR & \\
\hline Christian & 09 & 06 & 03 & 15 & 08 & 09 & \\
\hline Muslim & 08 & 10 & 02 & 13 & 07 & 10 & \\
\hline Hindu & 08 & 09 & 04 & 13 & 06 & 10 & \\
\hline
\end{tabular}

Source: Sample Survey

(Figure in brackets is p-value, * indicates significance at 5\% level.)

As the table suggests there is no association between risk perception and religion. $\left(\chi^{2}=2.34, p=0.9931\right)$.

Table 7: Reason behind Online Shopping in the Presence of Perceived Risk

\begin{tabular}{|c|c|c|c|c|c|c|c|c|}
\hline \multirow[t]{2}{*}{ Income (R.s) } & \multicolumn{7}{|c|}{ Reasons } & \multirow{4}{*}{$\begin{array}{l}\chi 2=22.68 \\
(0.2032)^{*}\end{array}$} \\
\hline & $\mathbf{A}$ & $\mathbf{B}$ & $\mathbf{C}$ & D & $\mathbf{E}$ & $\mathbf{F}$ & $\mathbf{G}$ & \\
\hline Below 10000 & 08 & 12 & 08 & 06 & 04 & 08 & 04 & \\
\hline $10000-20000$ & 07 & 14 & 09 & 08 & 03 & 06 & 03 & \\
\hline
\end{tabular}




\begin{tabular}{||l|l|l|l|l|l|l|l|l||}
\hline $20000-50000$ & 06 & 10 & 04 & 09 & 07 & 12 & 00 & \\
\cline { 1 - 6 } Above 50000 & 05 & 11 & 02 & 11 & 09 & 12 & 00 & \\
\hline
\end{tabular}

Source: Sample Survey

(Figure in brackets is p-value, * indicates significance at $5 \%$ level.)

Where, A- Trust in exchange process B- To get wide variety choices C- Growing tendency of banking and network facilities D- Time saving E- Economic incentive F- Easy access G- Not yet cheated so far.

It is noted that there are no differences in the reasons behind the online shopping even in the presence of perceived risk.

\section{Conclusion}

This paper investigates the risk perception in online shopping. Online shopping has a bright future in India for a variety of reasons. Easy accessibility, variety of choices, rate comparisons, the availability of feedback on the products etc. are some of the important factors that boosts up the scope of online shopping. However, the risks associated with online shopping are an important constraint which should be adequately addressed to boost the morale of online shoppers. Majority of the online shoppers opined that there are various types of risks such as product risk, time risk, financial risk etc. associated with online shopping. However, risk perception of the online shoppers is not significantly related to their income, sex, religion and education. Thus measures should be taken by online companies to mitigate various types of risks associated with online shopping.

\section{References}

[1] Bauer R.A, (1960). Consumer behaviour as risk taking: In Dynamic Marketing for a Changing World (Ed.) Hancock, R.S. Chicago: American Marketing Association, PP. 389.398.

[2] Cunningham, S.M. (1967). The major dimensions of perceived risk, In Risk taking and Information handing in Consumer behavior, ed. D.F. Cox, Boston, MA: Harvard University Press.

[3] Herrero Crespo; A., Boque, R, and Gracia, M. (2009). The Influence of perceived risk on Internet Shopping behaviour: A multidimensional perspective. Journal of Risk Research, Vol. 12.

[4] Jacoby, J., and B. Kaplan (1972). The components of perceived risk. In proceedings of the Third Annual Conference of the Association for Consumer Research

[5] J. Deborah, Risk Perception and internet shopping: Comparing United States and Saudi Arabian Consumers, University of South Carolina.

[6] MoudiAlmousa, The Influence of Risk Perception in Online Purchasing Behaviour: Examination of an Early-Stage online market, Department of Food Securities and Human Nutrition, King Saud University, Riyadh, Saudi Arabia.

*Corresponding author.

E-mail address: shafeequeaps@gmail.com 